\section{Bacterial enteritis in an oriental white backed vulture (Gyps bengalensis) and its successful management}

\author{
Vijay Kumar, ${ }^{1}$ Prasenjit Dhar, ${ }^{2}$ \\ Mandeep Sharma, ${ }^{2}$ Anshu Raj ${ }^{3}$ \\ 1Wild life, Dhauladhar Nature Park, \\ Gopalpur, Kangra; 2Department of \\ Veterinary Microbiology, Veterinary \\ College, Palampur; ${ }^{3}$ Deol, BaijNath, \\ Kangra, Himachal Pradesh, India
}

whether it and diclofenac poisoning occur widely across the subcontinent or there is also some other factors.

Escherichia coli (E. coli) is a normal inhabitant of the intestinal tracts of birds and animals. ${ }^{6}$ When an imbalance occurs in bacterial flora of the intestinal tract, $E$. coli may grow and cause an outbreak of colibacilliosis or enteritis. Enteritis caused by $E$. coli is one of the most import disease in domestic birds but hardly any incidences have been reported in vulture. The present communication puts on record an unusual incidence of bacterial enteritis in an oriental white backed vulture (Gyps bengalensis) and its successful treatment in the state of Himachal Pradesh, India.

\begin{abstract}
An oriental white backed vulture weighing about $8 \mathrm{~kg}$ was rescued from a farmer's field in a moribund condition. The vulture was showing signs of drooping feathers and wings, anorexia, unable to stand, and severe enteritis with dehydration. Bacterial culture from the cloaca of the bird revealed association of hemolytic $E$. coli that was sensitive to enrofloxacin and ciprofloxacin. The bird was treated successfully with injectable enrofloxacin and oral rehydration solution. No parasitic eggs/protozoal oocysts or hemoprotozoan parasites could be detected in the bird. The bird recovered uneventfully and started taking feed and water normally.
\end{abstract}

\section{Introduction}

Vultures are considered as nature's scavengers mainly feeding on dead and decaying animal matter. Recently, they are also among one of the most endangered species of animals. Populations of mainly three species of vulture i.e. oriental white backed vulture (OWBV; Gyps bengalensis), long-billed vulture (LBV; Gyps indicus) and slender-billed vulture (Gyps tenuirostris) in the Indian subcontinent have declined by more than $95 \%$ in the last 10 years ${ }^{1,2}$ leading the International Union of the Conservation of Nature to enlist the vulture among the most endangered species.

There are various infectious as well as non infectious factors which resulted in decline of vulture population. Apart from the established factors like pesticide residues, diclofenac leading to extensive deposition of uric acid on and within internal organs eventually leading their death due to renal failure ${ }^{1,3,4}$ other factors may also play important role in the decline in the vulture population. Although visceral gout has been reported previously from vultures in India $^{5}$ it is not yet clear

\section{Case Report}

An oriental white backed adult female vulture weighing around $8 \mathrm{~kg}$ was rescued from a farmer's field in Hamirpur Distt of Himachal Pradesh and was brought to Dhauladhar Natural Park - Gopalpur, Distt Kangra of Himachal Pradesh, India in a critical condition. The vulture was in a moribund state with drooping feathers and wings. On external examination, the vulture was found to be showing signs of severe enteritis like soiling of the vent feathers with pasty green feces that had an offensive odor. The bird was anorectic and exhibited drooping of head and neck with signs of dehydration and was unable to stand on its feet.

No external signs of any lesion or injury was observed on the body or feet of the bird. The temperature, heart rate, pulse rate and respiratory rates were however found to be within normal limits. The bird was restrained in lateral recumbency and the bill of the bird was taped to prevent self injury or injury to personnel (Figure 1).

The bird was initially orally rehydrated with oral rehydration solution solution at $30 \mathrm{~mL}$ before any systematic treatment was started. As the bird was showing signs of enteritis without any other clinical sign, it was decided to send fecal samples and blood for bacterial culture and sensitivity studies. For this, cloacal swabs in duplicate were taken in sterile normal saline and sent to the Department of Veterinary Microbiology, College of Veterinary and Animal Sciences, CSKHPKV, Palampur, Himachal Pradesh on ice for microbial isolation and drug sensitivity study. Blood samples (about $2 \mathrm{~mL}$ ) of the bird was also taken from the wing vein and sent to the laboratory to check for any generalized septicaemic infection or hemoprotozoan parasite. Fecal samples were also collected to check for the presence of intestinal parasitic eggs and protozoal oocysts. No attempts were made to isolate viruses from
Correspondence: Vijay Kumar, Dhauladhar Nature Park, Gopalpur, kangra, H.P. 176059 India. Tel. +91.945.913.3330.

E-mail: drvijay0220@gmail.com

Key words: Gyps bengalensis, enteritis, E. coli, enrofloxacin.

Contributions: VK, AR, treatment and sample collection; PD, MS, lab reports and compilation of the work.

Conflict of interest: the authors report no conflicts of interest.

Received for publication: 13 October 2011.

Revision received: 13 December 2011.

Accepted for publication: 13 January 2012.

This work is licensed under a Creative Commons Attribution NonCommercial 3.0 License (CC BYNC 3.0).

(C) Copyright V. Kumar et al., 2012

Licensee PAGEPress srl, Italy

Veterinary Science Development 2012; 2:e1

doi:10.4081/vsd.2012.e1

these samples due to lack of virus isolation facility.

\section{Results}

The cloacal samples and blood were immediately processed in the laboratory using routine bacteriological techniques. Briefly the swab was inoculated onto sterile blood agar media (containing 5 per cent defibrinated sheep blood), McConkey's lactose agar media (MLA) (Merck India limited), thioglycollate broth (Himedia India limited, Mumbai) and Sabouraud's dextrose agar (SDA) media (Himedia India limited, Mumbai). Selenite broth was also inoculated with these swabs for enrichment of Salmonella. All the inoculated media was incubated at $370 \mathrm{C}$ for 24 hours. After incubation, the enrichment broth culture was inoculated onto MLA, Hektoen enteric agar (HEA) and Brilliant green agar (BGA). The plates were again incubated at $37^{\circ} \mathrm{C}$ for 24-48 hours. SDA plates were incubated at $25^{\circ} \mathrm{C}$ for 10 days for identification of fungi.

After 24 hours of incubation, the plates were examined for different bacterial types. Pure hemolytic cultures of large, gray colored colonies were observed on blood agar media and pink colonies (lactose fermenting) were observed on MLA media while pure colonies exhibiting metallic sheen were observed on EMB agar. An oxidase test was performed on the given culture using $1 \%$ aqueous tetramethyl-p-phenylenediamine dihydrochloride (Himedia India limited, Mumbai). The culture 
was found to be oxidase negative. Motility test showed the organism to be motile. The lactose fermenting colonies were reinoculated to Eosin Methylene Blue agar (HiMedia India Limited) and colonies producing metallic sheen were transferred to nutrient agar slants and incubated at $37^{\circ} \mathrm{C}$ for 24 hours and stored at $4^{\circ} \mathrm{C}$ for further identification.

Identification of the isolate was based on staining and bio-chemical tests (Catalase, 0xidase, Indole, Methyl Red, VP test, Citrate utilization, Nitrate reduction, $\mathrm{H}_{2} \mathrm{~S}$ production in TSI and Urease). ${ }^{7}$ No growth was however recorded in thioglycollate medium or SDA even after 10 days of incubation implying absence of any fungal or anaerobic organism in the cloacal culture. The culture was negative for Salmonella sp. Blood sample of the bird did not yield any bacterial culture.

Additionally, 1 to $2 \mathrm{~g}$ of fecal sample, was examined by centrifugal flotation in concentrated $\mathrm{NaCl}$ and $\mathrm{ZnSO}_{4}$ solution to detect parasitic eggs. ${ }^{8}$ Blood smears made from the collected bird were stained with both Leishman and Giemsa stain for obtaining hematological readings and to check for any hemoprotozoal involvement.

Antibiograms: Antibiotic sensitivity assay were performed using the high-concentration single disk method. ${ }^{9}$ The isolated organism was subjected to antibiotic assay against a range of antibiotics viz. flouroquinolones [ciprofloxacin (Cf/10 $\mu \mathrm{g})$, enrofloxacin (Ex/30 $\mu \mathrm{g})$, norfloxacin $(\mathrm{Nx} / 10 \mu \mathrm{g})$ ], aminoglycosides [streptomycin $(\mathrm{S} / 10 \mu \mathrm{g})$, gentamicin $(\mathrm{G} / 10 \mu \mathrm{g})$, kanamycin $(\mathrm{K} / 30 \mu \mathrm{g})]$, Penicillin and its derivatives [penicillin (P/10 U), ampicillin (A/25 $\mu \mathrm{g})$, amoxicillin (Am/25 $\mu \mathrm{g})$ ], gut acting Colistin $(\mathrm{Cl} / 10 \mu \mathrm{g})$, Tetracycline (T/10 $\mu \mathrm{g})$, Metronidazole ( $\mathrm{Mt} / 5 \mu \mathrm{g})$, Furazolidone ( Fr/ $50 \mu \mathrm{g}$ ) incubated for 24 hours and the findings recorded.

The cultural characteristics, gram staining, oxidase reaction, motility and biochemical pattern (IMViC pattern) and carbohydrate fermentation tests of the culture matched with that of hemolytic Escherichia coli (E. coli) (Table 1). Fecal examination of the bird did not reveal the presence of any parasitic eggs or ova. Blood smear examination also failed to detect any hemoprotozoan parasite though it showed slight increase in heterophils without increase in any other cellular component. The E. coli isolate could not be typed due to lack of necessary facility.

Drug sensitivity of the organism revealed highest sensitivity to the flouroquinolones (enrofloxacin, ciprofloxacin and norfloxacin) (100 per cent). Moderate sensitivity was noticed for aminoglycosides (gentamicin, streptomycin, kanamycin), tetracycline, colistin, metronidazole and furazolidone. The organism was however found to be resistant to penicillin, ampicillin and amoxicillin.
As the organism was sensitive to enrofloxacin, the bird was continuously treated with injectable Enrocin (Enrofloxacin) (Intas Pharmaceuticals Pvt. Limited, India) $(100 \mathrm{mg} / \mathrm{mL})$ at $40 \mathrm{mg}, \mathrm{i} / \mathrm{m}$ on thigh muscle once a day for five days and injection Tribivet (B complex vitamins) (Intas Pharmaceuticals Pvt.Limited,India) at $0.4 \mathrm{~mL} / \mathrm{i} / \mathrm{m}$ on alternate days on three occasions. Oral rehydration therapy was continued for seven days at $30 \mathrm{~mL}$ b.i.d. The bird recovered uneventfully to normal health (Figure 2) and started taking feed. Fresh chicken or mutton at $250-500$ gms were provided for the bird with ad lib water.

\section{Discussion}

Vultures are scavenging birds, and this frequently predisposes them to different types of poisoning. ${ }^{10}$ In addition, vultures instinctively feed in large groups, because carcasses are scarce in space and time, and feeding often incurs fighting and wounding, exposing vultures to the penetration of microorganisms present in the carrion. ${ }^{11}$ Therefore, vultures have evolved immune mechanisms to cope with a high risk of infection with virulent parasites. However, vultures are usually not susceptible to enteritis due to a highly corrosive stomach acid that can withstand botulinum and anthrax toxin.

Intestinal microflora composition of scavenger's however has been known to be mainly dependent on their diet.12 Although some authors consider that bacteria from the genus Enterobacteriaceae are not traditional intestinal flora of Falconiformes and Accipitriformes, ${ }^{13,14}$ Houston and Cooper (1975) reported that gram negative bacilli of the family Enterobacteriaceae, especially $E$. coli, appeared to be normal inhabitant of the white back griffon vulture's intestinal tract and some other members of the Falconiformes because the majority of their intestinal flora were probably derived from their prey. E. coli is normally present in birds and the disease due to $E$. coli can be triggered by a variety of events. Immunosuppression due to diseases, fighting, mating stress may increase susceptibility of birds to $E$. coli infection. For instance in domestic poultry, an $E$. coli infection may appear if birds do not have regular access to feed or if their litter is too wet or if they are exposed to another disease. Generally, anything that causes stress in the bird may provide $E$. col $i$ with the opening it needs to produce infection. 15 Symptoms of $E$. coli infection in birds include respiratory disease from air sac infection, a septicemic (blood) disease from generalized infections, an enteritis from intestinal infection or a combination of any or all of these conditions. Profuse diarrhea and

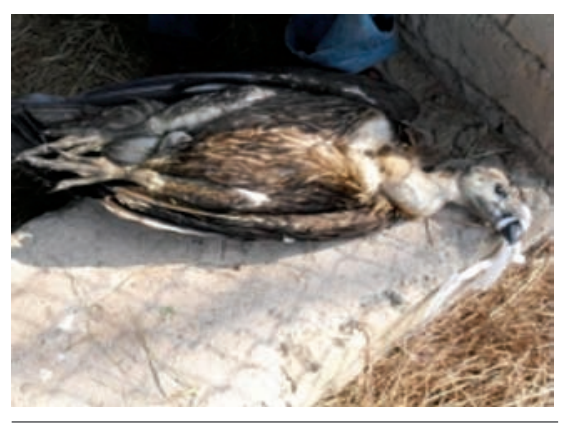

Figure 1. Vulture in moribund condition.

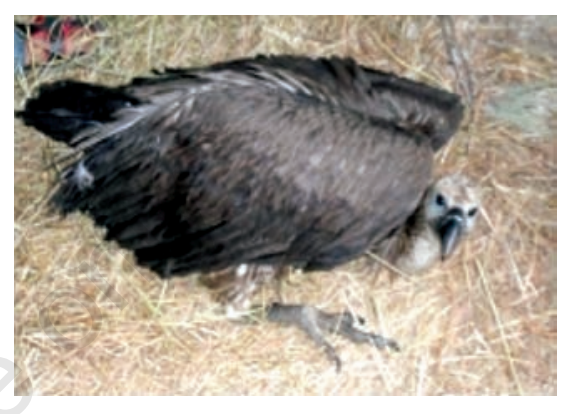

Figure 2. Recovery of bird after treatment.

Table 1 Biochemical characteristics of the $E$. coli isolate recovered from white backed vulture.

\begin{tabular}{lc}
\hline Cest & $\begin{array}{c}\text { Reaction } \\
\text { Gram negative } \\
\text { small bacilli }\end{array}$ \\
Oxidase test & $(-)$ \\
\hline Catalase test & $(+)$ \\
Motility & $(+)$ \\
\hline Hemolysis & $(+)$ \\
Indole production & $(+)$ \\
\hline Methyl Red & $(+)$ \\
Voges-Proskauer & $(-)$ \\
\hline Citrate & $(-)$ \\
Urease & $(-)$ \\
\hline Hydrogen sulphide production & $(-)$ \\
Nitrate reduction & $(+)$ \\
\hline Gelatin liquefaction & $(-)$ \\
Acid fast & \\
\hline Glucose & $(+)$ \\
Lactose & $(+)$ \\
\hline Sucrose & $(+)$ \\
Maltose & $(+)$ \\
\hline Mannitol & $(+)$ \\
Mannose & $(+)$ \\
\hline Sorbitol & $(+)$ \\
\hline Rhamnose & $(+)$ \\
\hline Dulcitol & $(-)$ \\
\hline Inositol & $(-)$ \\
\hline
\end{tabular}


rapid deterioration are the usual symptoms of a $E$. coli infection. The primary routes of invasion by the organism are the respiratory system and the gastrointestinal tract.

The classification of $E$. coli strains infecting birds are known to be difficult, and the pathogenesis of infection is also poorly defined. The serologic and virulence factors used to classify the $E$. coli strains that infect humans and other mammals do not accurately predict which $E$. coli strain will be pathogenic in birds. All bacteria isolated from vultures can potentially be spread to other wildlife or human population passively on the bird's feet, feathers, faeces or regurgitated food items and can be the cause of diseases, especially $E$. coli.16,17 However, due to insufficient information in the literature, further research is needed to understand the potential role of white backed vultures in dissemination and transmission of pathogens to wildlife and possibly humans, as well as potential negative effects of pathogens like hemolytic $E$. coli to the vulture population health and conservation status, which has already been noted by other authors. 16,18

Although the prevalence of $E$. coli in vultures have been recorded by earlier authors ${ }^{19}$ who reported the presence of $E$. coli in more than 90 per cent of apparently healthy turkey vultures in his study and Houston and Cooper (1975) ${ }^{11}$ who found associations of E. coli, Citrobacter freundii, and Proteus vulgaris from white back Griffon's vultures (Gyps africanus) in Africa, the present study highlights the association of $E$. coli with clinical enteritis in vultures.

The recent report shows that $E$. coli can cause enteritis in these scavengers. Enteritis in birds both domestic and wild can be caused by a variety of pathogens like Salmonella, Pasteurella, Adenovirus, IBD, circovirus etc. In this case, the recovery of $E$. coli in pure culture, an altered blood picture of heterophilia suggests that the etiology of the enteritis was bacterial in nature as all other underlying causes (endoparasites, fungi, anaerobic bacteria, hemoprotozoan) were excluded. Though, no attempts were made to isolate any virus from this case, the total absence of a viral induced blood picture and the instant recovery of the bird following treatment with organism specific antibiotic therapy suggests that the etiology was bacterial. As in vitro sensitivity assay of the organism revealed susceptibility to enrofloxacin, the same antibiotic was used that led to rapid improvement in the bird. Susceptibility of the E. coli isolates to flouroquinolones is also supported by the work of Sharda et al. (2009) ${ }^{20}$ who found their poultry E. coli isolates to be highly susceptible to flouroquinolones. Though different reports of enteritis in live and dead vultures have been reported by various authors either due to diclofenac toxicity 3,4 or due to lead poisoning 19 or due to methomyl, 21 carbofurans, ${ }^{22}$ this appears to be the first report of the association of $E$. coli with enteritis in vultures.

\section{Conclusion}

This study revealed that intestinal bacteria like $E$. coli that are considered to be normal commensals of the gastrointestinal tract can suddenly acquire pathogenic potential under conditions of stress or depressed immune system. We could not however definitely conclude the factors that predisposed the bird to enteritis, whether this was due to an indigenous $E$. coli strain suddenly acquiring pathogenic potential or the infection was extraneous in origin. However, the successful management of the case offers hope of similar treatment protocols in future and an insight that pathogens like $E$. coli can cause enteritis in natural scavengers like vultures.

\section{References}

1. Prakash V. Status of vultures in Keoladeo national park, Bharat pur, Rajasthan, with speical reference to population crash in gyps species. J Bombay Ntrl Hist Soc 1999; 96:365-78.

2. Oaks JLM, Gilbert MZ, Virani RT, et al. Diclofenac residues as the cause of vulture population decline in Pakistan. Nature 2004;2317:1-4.

3. Shultz S, Baral HS, Charman S, et al. Diclofenac poisoning is widespread in declining vulture populations across the Indian subcontinent. Proc Biol Sci 2004; 271:S458-60.

4. Sharma SK, Prasad G, Minakshi MY, et al. Vulture mortality: pathological and microbiological investigations. Ind J Anim Sci 2002; 72:283-6.

5. Cunningham AA, Prakash V, Pain D, et al. Indian vultures: victims of an infectious disease epidemic? Anim Conserv 2003;6: 189-97.

6. Barnes HJ, Vaillancourt JP, Gross WB. Colibacillosis. In: Diseases of Poultry, 11th ed. Ames: Iowa State University Press; 2003.

7. Kreig NR, Holt JG, Williams W. Bergeys manual of systematic bacteriology, Vol. 1. Baltimore: East Preston street; 1984.

8. Faust EC, Sawit W, Toble J, et al. Comparative efficiency of various techniques for diagnosis of protozoa and helminthes in feces. J Parasitol 1939;25: 241-62.
9. Bauer AW, Kirby WMM, Sheris JC, Truck M. Antibiotic susceptibility testing by a standardized single disc method. Am J Clin Pathol 1966;145:225-30.

10. Blanco G, Lemus JA, Grande J, et al. Geographical variation in cloacal microflora and bacterial antibiotic resistance in a threatened avian scavenger in relation to diet and livestock farming practices. Environ Microbiol 2007;9:1738-49.

11. Houston DC, Cooper JE. The digestive tract of the whiteback griffon vulture and its role in disease transmission among wild ungulates. J Wildl Dis 1975;11:306-13.

12. Gerlach H. Bacteria. In: Ritchie BW, Harrison GJ, Harrison LR. Avian med principles and application. Lake Worth: Wingers; 1994. pp 949-983.

13. Tizard I. Salmonellosis in wild birds. Semin Avian Exot Pet 2004;13:50-66.

14. Durairaj V, Clark FD. E. coli an opportunist that causes enteritis. 2007. Available from: http://www.thepoultrysite.com/articles/903/ie-coli-ian-opportunist-that-causes-enteritis

15. Friend M, McLean RG, Dein J. Disease emergence in birds: challenges for the twenty-first century. Auk 2001;118:290303.

16. Hubalek Z. An annotated checklist of pathogenic microorganisms associated with migratory birds. J Wildl Dis 2004;40:63959.

17. Rodrigues L, Macedo L, Robert J, et al. Dominant culturable bacterial microbiota in the digestive tract of the American black vulture (Coragyps atratus Bechstein 1793) and search for antagonistic substances. Braz J Microbiol 2003;34:218-24.

18. Winsor DK, Bloebaum AP, Mathewson JJ. Gram negative aerobic enteric pathogens among intestinal microflora of wild turkey vultures (Cathartes aura) in West Central Texas. Appl Environ Microbiol 1981;42: 1123-4.

19. Pattee OH, Carpenter JW, Fritts, SH, et al. Lead poisoning in captive andean condors (Vultur gryphus). J Wildl Dis 2006;42:7729.

20. Sharada R, Ruban SW, Thiyageeswaran M. Antibiotic resistance pattern of Escherichia coli isolated from Poultry in Bangalore. Int J Microbiol 2009;7.

21. Sabocanec R, Konjević D, Srebočan E, Petrinec Z. Fatal poisoning of a griffon vulture (Gyps fulvus) with methomyl. Eur J Wildl Res 2005;51:210-2.

22. Pavokovic G, Susic G. Poisoning of 17 Eurasian griffons by carbofuran on the Island of Rab, Croatia, in December 2004. Vulture News 2005;53:24-5. 